\title{
Patient Characteristics and Utilization Patterns of Short-Acting Recombinant Granulocyte Colony-Stimulating Factor (G-CSF) Biosimilars Compared to Their Reference Product
}

\author{
Aaron B. Mendelsohn ${ }^{1}$ (D) James Marshall ${ }^{1}$. Cara L. McDermott ${ }^{2}$ (D) Pamala A. Pawloski $^{3}$ (D) . Jeffrey S. Brown ${ }^{1}$ (D) \\ Catherine M. Lockhart ${ }^{2}$ (1)
}

Accepted: 16 January 2021 / Published online: 30 January 2021

(C) The Author(s) 2021

\begin{abstract}
Background Data on short-acting recombinant granulocyte colony-stimulating factor (G-CSF) biosimilar utilization from claims data in the USA are limited.

Objective To evaluate patient baseline characteristics and utilization patterns for short-acting G-CSF products with particular focus on the assessment of filgrastim biosimilar usage relative to the originator product.

Patients and methods We examined filgrastim, filgrastim-sndz, and tbo-filgrastim use among adult patients between January 2012 and March 2019 across the five health-plan research partners in the BBCIC Distributed Research Network. The publicly available Sentinel System analytic toolkit was used to perform the distributed analyses.

Results We evaluated over 38 million eligible health-plan members representing more than 88 million person-years of data. We identified 45,204 incident treatment episodes, including 33,118 episodes with filgrastim, 6525 episodes with filgrastimsndz, and 5,561 episodes with tbo-filgrastim. We observed that the demographic and clinical characteristics of users were comparable across products. While total use of all filgrastim products remained consistent, the proportion of incident episodes of the originator filgrastim steadily decreased since 2014, with filgrastim-sndz and tbo-filgrastim making up the difference. Utilization for the G-CSF biosimilar, filgrastim-sndz, increased from 40 (1\%) of 6823 total filgrastim product episodes in 2015, to 2486 (44\%) of a total 5668 episodes of filgrastim products in 2018 (partial data for 2018).

Conclusion New episodes of short-acting biosimilar filgrastim products have increased over time while the overall number of new users remained flat. Although barriers to biosimilar use in oncology have been noted, uptake has begun and continues to grow.
\end{abstract}

This research was accepted for presentation at the 2020 National Comprehensive Cancer Network Annual Conference and was presented virtually after the meeting was canceled due to the Covid-19 outbreak.

Catherine M. Lockhart

clockhart@bbcic.org

1 Harvard Pilgrim Health Care Institute, Harvard Medical School, Boston, MA, USA

2 Biologics and Biosimilars Collective Intelligence Consortium (BBCIC), 675 North Washington Street, Suite 220,

Alexandria, VA, USA

3 HealthPartners Institute, Minneapolis, MN, USA

\section{Key Points}

Filgrastim biosimilar utilization is on the rise and represents a growing share of total short-acting G-CSF use.

Real-world evidence on clinical outcomes for the shortacting G-CSF biosimilar versus the originator product is important as biosimilar use continues to increase in the coming years. 


\section{Introduction}

Short-acting recombinant granulocyte colony stimulating factors (G-CSFs; filgrastim (Neupogen ${ }^{\circledR}$ ), tbo-filgrastim $\left(\right.$ Granix $\left.^{\circledR}\right)$ ) are used as both prophylaxis and treatment of severe or febrile neutropenia caused by myelosuppressive chemotherapy [1-4]. In 2015, the US Food and Drug Administration (FDA) approved the first filgrastim biosimilar, filgrastim-sndz $\left(\operatorname{Zarxio}^{\circledR}\right)$, for prophylaxis and treatment of chemotherapy-induced neutropenia, with a second biosimilar, filgrastim-aafi (Nivestym ${ }^{\circledR}$ ) being approved in 2018 [5]. Biosimilars have the potential to reduce treatment costs [6]. The available data on G-CSF biosimilar utilization through the analysis of claims data in the USA have been limited, though studies have suggested increased filgrastim biosimilar uptake over time [7, 8]. Additional data from diverse sources can help quantify variation in biosimilar use.

The Biologics and Biosimilars Collective Intelligence Consortium (BBCIC) is a non-profit, multi-stakeholder, research consortium dedicated to investigating the realworld safety and effectiveness of biologic drugs, including biosimilars, in the USA [9]. The BBCIC Distributed Research Network (DRN) provides administrative claims data for approximately 95 million patient years across five research partners including two large national health insurers (Healthagen (Aetna), HealthCore (Anthem)) and three regional health plans or integrated delivery networks (Harvard Pilgrim Health Care, HealthPartners, Kaiser Permanente of Washington). The BBCIC DRN Research Partners participate in the FDA Sentinel System, enabling the consortium to leverage the Sentinel System's infrastructure, including the Sentinel Common Data Model and curated data resources for data standardization, and analytic tools for conducting distributed analyses [10, 11]. Periodic queries are conducted in the BBCIC DRN to monitor utilization of medications of interest. In this report, we provide a high-level summary of utilization and patient characteristics of short-acting G-CSF users in the BBCIC DRN.

\section{Methods}

Adult patients receiving any short-acting G-CSF between 1 January 2012 and as recent as 31 March 2019 were identified across the five health-plan Research Partners in the BBCIC DRN. Some Research Partners provided data through part of 2018; this was accounted for in the denominator of our calculations. Medications of interest included filgrastim, filgrastim-sndz, and tbo-filgrastim. We did not include filgrastim-aafi in these analyses as the product was only recently made available toward the end of the study period. Additionally, given the low utilization of sargramostim (Leukine ${ }^{\circledR}$ ) in the USA [12] and that a biosimilar for sargramostim is not available in the USA, we did not include this product in our study.

All patients were required to have medical and pharmacy coverage and be enrolled for a minimum 183 days prior to the first observed short-acting G-CSF utilization date (index date) during the period noted above. An enrollment gap of 45 days was permitted. Incident use was defined as having no exposure to a given medication in the 183 days before the index date. We examined the number of incident use episodes for each medication of interest, overall and according to patient demographic and clinical characteristics (e.g., comorbid conditions). Patients could contribute multiple "incident" episodes for the same or different drugs if they met the eligibility criteria, including the 183-day washout period, each time. Demographic characteristics were measured on the index date, and clinical characteristics were assessed during the 183-day period before the index date ("baseline period"). The publicly available Sentinel System analytic toolkit (Cohort ID and Descriptive Analysis (CIDA v8.1.0)) was used to perform the distributed analyses [13]. Products of interest were identified using J-codes from Healthcare Common Procedure Coding System or National Drug Codes (NDCs). The complete list of codes used in this analysis can be found at https://www.bbcic.org/research/ completed-research.

Distributed analyses were conducted by each Research Partner, with results aggregated for final analysis. Cells with counts $<10$ are not presented to protect the anonymity of patients, per standard BBCIC practice. Institutional Review Boards for the participating Research Partners determined that this work does not meet the definition of human subjects research.

\section{Results}

Over 38 million eligible health plan members representing more than 88 million person-years of data were evaluated from the BBCIC DRN. A total of 45,204 incident treatment episodes were identified, including 33,118 episodes with filgrastim, 6525 episodes with filgrastim-sndz, and 5561 episodes with tbo-filgrastim (Table 1). The age distribution was similar across treatments, and females accounted for $58.2 \%$ of filgrastim patients, $61.1 \%$ of filgrastim-sndz, and $58.5 \%$ of tbo-filgrastim patients. The mean combined comorbidity index score [14] was $5.4(\mathrm{SD}=3.3)$ for originator filgrastim episodes and 6.0 $(\mathrm{SD}=3.5)$ for filgrastim-sndz. Other clinical characteristics were comparable across the filgrastim products. 
Table 1 Patient baseline characteristics for incident use of filgrastim products. The Biologics and Biosimilars Collective Intelligence Consortium (BBCIC) Distributed Research Network, January 2012-March 2019

\begin{tabular}{|c|c|c|c|}
\hline \multirow[t]{2}{*}{ Total number of episodes } & \multicolumn{3}{|l|}{$N=45,204$} \\
\hline & Filgrastim (Neupogen ${ }^{\circledR}$ ) & $\begin{array}{l}\text { Filgrastim- } \\
\text { sndz }\left(\text { Zarxio }^{\circledR}\right)\end{array}$ & $\begin{array}{l}\text { tbo- } \\
\text { Filgrastim } \\
\left(\text { Granix }^{\circledR}\right)\end{array}$ \\
\hline \multicolumn{4}{|l|}{ G-CSF exposure episodes } \\
\hline Patients contributing to cohort ${ }^{\mathrm{a}}, n$ & 31,023 & 6305 & 5325 \\
\hline GCSF episodes $^{\mathrm{a}}, n$ & 33,118 & 6525 & 5561 \\
\hline \multicolumn{4}{|l|}{ Patient characteristics } \\
\hline Mean (SD) age, years & $59.8(13.6)$ & $59.8(13.2)$ & $60.5(13.1)$ \\
\hline Female, $\%$ & 58.2 & 61.1 & 58.5 \\
\hline \multicolumn{4}{|l|}{ Age groups ${ }^{\mathrm{b}}, n(\%)$} \\
\hline $18-49$ years & $6758(20.4)$ & 1409 (21.6) & $1023(18.4)$ \\
\hline 50-64 years & $14,734(44.5)$ & $2869(44.0)$ & $2524(45.4)$ \\
\hline $65-79$ years & $9690(29.3)$ & $1896(29.1)$ & $1709(30.7)$ \\
\hline $80+$ years & $1936(5.8)$ & $351(5.4)$ & $305(5.5)$ \\
\hline \multicolumn{4}{|l|}{ Clinical characteristics by exposure episode ${ }^{\mathrm{c}}, n(\%)$} \\
\hline Combined Comorbidity Index, mean (SD) & $5.4(3.3)$ & $6.0(3.5)$ & $6.1(3.5)$ \\
\hline Breast cancer & $7038(21.3)$ & $1669(25.6)$ & $1153(20.7)$ \\
\hline Lung cancer & $4343(13.1)$ & $692(10.6)$ & $769(13.8)$ \\
\hline Breast chemotherapy_GCSF prophylaxis & $4052(12.2)$ & $891(13.7)$ & $740(13.3)$ \\
\hline Lung chemotherapy - GCSF prophylaxis & $88(0.3)$ & $18(0.3)$ & $26(0.5)$ \\
\hline Breast chemotherapy-GCSF treatment & $6608(20.0)$ & $1374(21.1)$ & $1168(21.0)$ \\
\hline Lung chemotherapy_-GCSF treatment & $134(0.4)$ & $26(0.4)$ & $33(0.6)$ \\
\hline Other chemotherapy & $21,613(65.3)$ & $4248(65.1)$ & $3673(66.0)$ \\
\hline Bone/stem cell transplant & $339(1.0)$ & $73(1.1)$ & $100(1.8)$ \\
\hline Cancer radiation & $5845(17.6)$ & $1115(17.1)$ & $1051(18.9)$ \\
\hline HIV/AIDS & $241(0.7)$ & $40(0.6)$ & $36(0.6)$ \\
\hline Neutropenia & $11,368(34.3)$ & $2513(38.5)$ & $2397(43.1)$ \\
\hline Anaphylaxis & $3515(10.6)$ & $1656(25.4)$ & $1204(21.7)$ \\
\hline Anemia & $17,295(52.2)$ & $3319(50.9)$ & $3106(55.9)$ \\
\hline Arthritis & $1578(4.8)$ & $319(4.9)$ & $290(5.2)$ \\
\hline Bone pain & $6642(20.1)$ & $1401(21.5)$ & $1179(21.2)$ \\
\hline Capillary leak syndrome & $51(0.2)$ & $<10(\mathrm{NC})$ & $<10(\mathrm{NC})$ \\
\hline Chronic obstructive pulmonary disease & $6755(20.4)$ & $1261(19.3)$ & $1212(21.8)$ \\
\hline Congestive heart failure & $2352(7.1)$ & $445(6.8)$ & $456(8.2)$ \\
\hline Glomerulonephritis & $145(0.4)$ & $20(0.3)$ & $27(0.5)$ \\
\hline Hyperleukocytosis & $3223(9.7)$ & $676(10.4)$ & $560(10.1)$ \\
\hline Kidney disorder & $1594(4.8)$ & $389(6.0)$ & $388(7.0)$ \\
\hline Lumpectomy/mastectomy & $2510(7.6)$ & $608(9.3)$ & $355(6.4)$ \\
\hline Metastatic bone cancer & $4572(13.8)$ & $910(13.9)$ & $810(14.6)$ \\
\hline Metastatic brain cancer & $1288(3.9)$ & $222(3.4)$ & $230(4.1)$ \\
\hline Metastatic disease & $11,237(33.9)$ & $2761(42.3)$ & $2179(39.2)$ \\
\hline Metastatic liver cancer & $3987(12.0)$ & $870(13.3)$ & 715 (12.9) \\
\hline Metastatic lung cancer & $2818(8.5)$ & $541(8.3)$ & $497(8.9)$ \\
\hline Peptic ulcer disease & $763(2.3)$ & $172(2.6)$ & $164(2.9)$ \\
\hline Poor nutritional status & $5530(16.7)$ & $1351(20.7)$ & $1095(19.7)$ \\
\hline Any cancer diagnosis (except breast cancer) & $23,312(70.4)$ & $4449(68.2)$ & $3921(70.5)$ \\
\hline Severe liver impairment & $3937(11.9)$ & 774 (11.9) & 745 (13.4) \\
\hline Splenic rupture & $63(0.2)$ & $15(0.2)$ & $<10(\mathrm{NC})$ \\
\hline Thyroid disorder & $5994(18.1)$ & $1250(19.2)$ & $1061(19.1)$ \\
\hline Antibiotics & $19,727(59.6)$ & $3724(57.1)$ & $3271(58.8)$ \\
\hline Endocrine drug products & $3183(9.6)$ & $620(9.5)$ & $534(9.6)$ \\
\hline
\end{tabular}


Table 1 (continued)

\begin{tabular}{llll}
\hline Total number of episodes & $N=45,204$ & \\
\cline { 2 - 4 } & Filgrastim $($ Neupogen & \\
& & $\begin{array}{l}\text { Filgrastim- } \\
\text { sndz }\left(\text { Zarxio }^{\circledR}\right)\end{array}$ & $\begin{array}{l}\text { tbo- } \\
\text { Filgrastim } \\
\left(\text { Granix }^{\circledR}\right)\end{array}$ \\
\hline Anti-osteoporosis medications & $715(2.2)$ & $111(1.7)$ & $85(1.5)$ \\
\hline
\end{tabular}

AIDS acquired immunodeficiency syndrome, GCSF granulocyte colony-stimulating factor, $H I V$ human immunodeficiency virus, $N C$ not calculated (for considerations of patient privacy counts less than 10 are specified as $<10$ and a percentage is unable to be calculated), $S D$ standard deviation

${ }^{a}$ Number of episodes is not equal to number of patients due to the relatively short (183-day) lookback period, so the same patient could contribute a second episode if the time between the last exposure and the new dispensing is $>183$ days, which would then be considered incident

${ }^{b}$ Number of episodes observed for patients in each age category contributing time to the exposure category

${ }^{c}$ Counts are based on the number of episodes in which a clinical characteristic of interest was observed in any care setting (e.g., inpatient, outpatient) in the 183-day lookback period prior to the episode index date

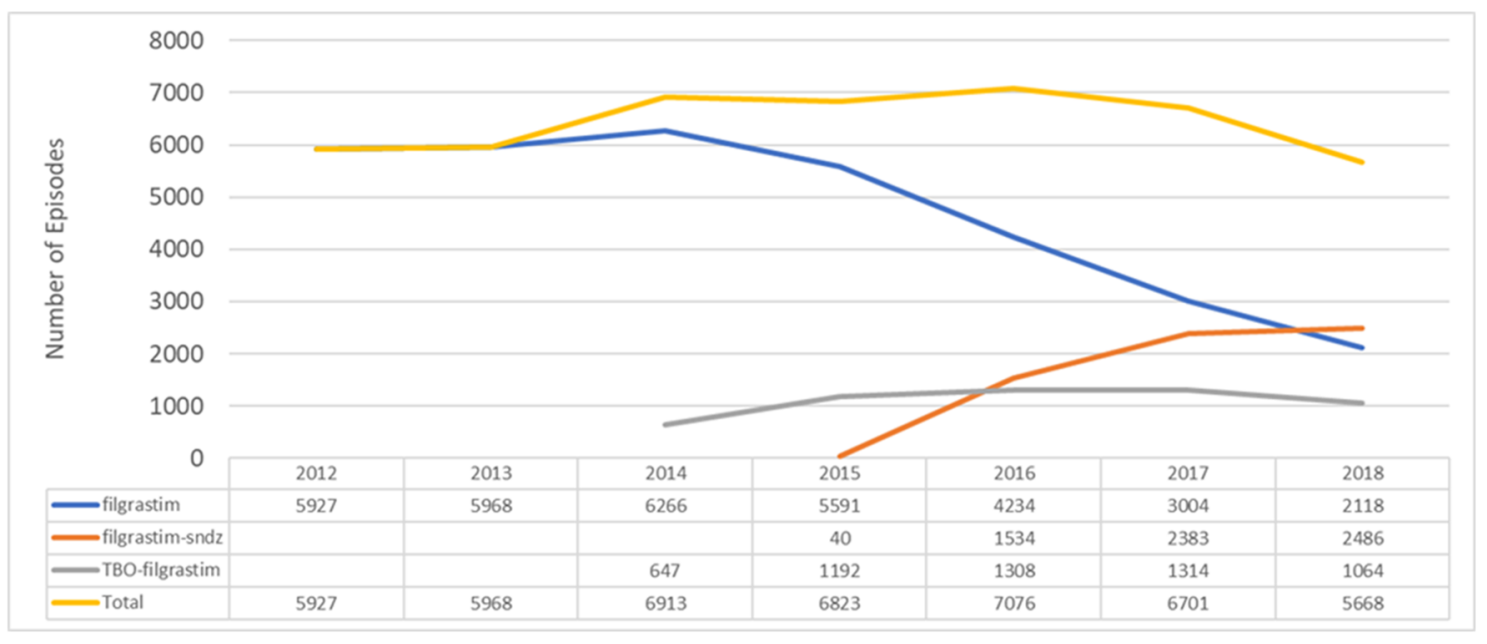

a Two Research Partners (of five total) had data through the end of 2018.

Fig. 1 Incident granulocyte colony-stimulating factor (filgrastim products) use over time. The Biologics and Biosimilars Collective Intelligence Consortium (BBCIC) Distributed Research Network, January 2012-March 2019

Total use of all filgrastim products remained consistent at about 6,500 incident episodes annually (Fig. 1); however, the proportion of incident episodes of filgrastim steadily decreased since 2014, with filgrastim-sndz and tbo-filgrastim making up the difference. Specifically, in the BBCIC DRN, tbo-filgrastim was available beginning in 2014 and accounted for 647 (9\%) of a total 6913 episodes of filgrastim products in that year. Utilization of tbo-filgrastim rose to 1314 (20\%) of 6701 total episodes in 2017. Utilization for filgrastim-sndz increased from 40 (1\%) of 6823 total filgrastim product episodes in 2015 to 2486 (44\%) of a total 5668 episodes of filgrastim products in 2018 (partial data for 2018).

\section{Discussion}

This systematic, longitudinal surveillance on short-acting G-CSF utilization patterns in the USA showed that new episodes of biosimilar filgrastim products have increased over time. Our study provides data demonstrating that although barriers to biosimilar use in oncology have been noted [15], uptake has begun and continues to grow. As more biosimilar products enter the market, we will be watching closely to evaluate whether or not biosimilar utilization distributes further among available options. The implications of biosimilar utilization in the USA are 
uncertain until greater overall utilization is observed, but, as noted, there is a potential for decreased cost of treatment with biosimilar products [6].

There are some limitations that need to be considered in interpreting these results. The BBCIC DRN data are generally representative of commercially insured individuals in the USA. These findings may not be applicable to other populations, for example, Medicare patients. Also, we were not able to fully evaluate trends in utilization for the later years of the study period given partial data for 2018 and 2019. Finally, there is the possibility of misclassification in identifying drug exposures and clinical characteristics through administrative claims data.

Given that the focus of this analysis was on biosimilar versus originator products, and that there were insufficient pegfilgrastim biosimilar data at the time of this study, our analysis was limited to short-acting filgrastim only. We previously found that pegfilgrastim represents approximately two-thirds of total incident G-CSF use in the BBCIC DRN [16] compared with short-acting filgrastim. We intend to perform similar analyses to the present study comparing utilization and patient characteristics among the pegfilgrastim products when sufficient data are available.

In sum, gaining additional real-world evidence on the clinical outcomes and comparative effectiveness of biosimilars compared to reference products is important as shortingacting G-CSF biosimilar use grows in the coming years.

Acknowledgements The authors would like to thank the following entities and individuals for their support of this research: the BBCIC Research Partners [Healthagen, HealthCore, HealthPartners, Kaiser Permanente of Washington, Harvard Pilgrim Health Care Institute (HPHCI)]; Sarah Malek (HPHCI); Dr. Young Hee Nam (HPHCI); and Katie Stewart (HPHCI at the time of study). Additionally, the authors are grateful to the BBCIC Science Committee for their review and input on earlier versions of the manuscript.

\section{Declarations}

Funding This study was funded by the Biologics and Biosimilars Collective Intelligence Consortium (BBCIC).

Conflict of interest All authors declare that they have no conflicts of interest.

Ethics approval Institutional Review Boards for the participating Research Partners in the BBCIC Distributed Research Network (DRN) determined that this work does not meet the definition of human subjects research.

Consent to participate Not applicable.

Consent for publication Not applicable.

Availability of data and material The data analyzed for this study are available from the corresponding author on reasonable request.

Code availability Not applicable.
Author contributions All authors contributed to the study conception and design. Data analysis was led by James Marshall with input and direction from all other authors. Catherine Lockhart and Aaron Mendelsohn prepared the first draft of the manuscript and all authors participated in the revision of the initial manuscript, and approved the final manuscript. All authors agree to be accountable for all aspects of the work.

Open Access This article is licensed under a Creative Commons Attribution-NonCommercial 4.0 International License, which permits any non-commercial use, sharing, adaptation, distribution and reproduction in any medium or format, as long as you give appropriate credit to the original author(s) and the source, provide a link to the Creative Commons licence, and indicate if changes were made. The images or other third party material in this article are included in the article's Creative Commons licence, unless indicated otherwise in a credit line to the material. If material is not included in the article's Creative Commons licence and your intended use is not permitted by statutory regulation or exceeds the permitted use, you will need to obtain permission directly from the copyright holder. To view a copy of this licence, visit http://creativecommons.org/licenses/by-nc/4.0/.

\section{References}

1. Chan A, Fu WH, Shih V, Coyuco JC, Tan SH, Ng R. Impact of colony-stimulating factors to reduce febrile neutropenic events in breast cancer patients receiving docetaxel plus cyclophosphamide chemotherapy. Support Care Cancer. 2011;19:497-504.

2. Elting LS, Xu Y, Chavez-MacGregor M, Giordano SH. Granulocyte growth factor use in elderly patients with non-Hodgkin's lymphoma in the United States: adherence to guidelines and comparative effectiveness. Support Care Cancer. 2016;24:2695-706.

3. Renner P, Milazzo S, Liu JP, Zwahlen M, Birkmann J, Horneber M. Primary prophylactic colony-stimulating factors for the prevention of chemotherapy-induced febrile neutropenia in breast cancer patients. Cochrane Database Syst Rev. 2012;10:CD007913.

4. Kuderer NM, Dale DC, Crawford J, Lyman GH. Impact of primary prophylaxis with granulocyte colony-stimulating factor on febrile neutropenia and mortality in adult cancer patients receiving chemotherapy: a systematic review. J Clin Oncol. 2007;25:3158-67.

5. US Food and Drug Administration. https://www.fda.gov/drugs /biosimilars/biosimilar-product-information. Accessed 17 Jan 2020.

6. Mulcahy AW, Hlavka JP, Case SR. Biosimilar cost savings in the United States: Initial experience and future potential. Rand Health Q. 2018;7(4):3.

7. Gawade PL, Li S, Henry D, et al. Patterns of granulocyte colony-stimulating factor prophylaxis in patients with cancer receiving myelosuppressive chemotherapy. Support Care Cancer. 2020. https://doi.org/10.1007/s00520-020-05295-2.

8. Chen X, Agiro A, Barron J, Debono D, Fisch M. Early adoption of biosimilar growth factors in supportive cancer care. JAMA Oncol. 2018;4(12):1779-81. https://doi.org/10.1001/jamao ncol.2018.5090.

9. Biologics and Biosimilars Collective Intelligence Consortium. www.bbcic.org. Accessed 4 Dec 2019.

10. Platt R, Brown JS, Robb M, et al. The FDA sentinel initiative-an evolving national resource. N Engl J Med. 2018;379(22):2091-3. 
11. Ball R, Robb M, Anderson SA, Dal Pan G. The FDA's sentinel initiative-a comprehensive approach to medical product surveillance. Clin Pharmacol Ther. 2016;99(3):265-8.

12. Henk HJ, Becker L, Tan H, Yu J, Kavati A, Naeim A, Deeter $\mathrm{R}$, Barron R. Comparative effectiveness of pegfilgrastim, filgrastim, and sargramostim prophylaxis for neutropenia-related hospitalization: two US retrospective claims analyses. J Med Econ. 2013;16:160-8.

13. The Sentinel Operations Center. Surveillance Tools: Routine Querying Tools (Modular Programs). https://www.sentinelin itiative.org/sentinel/surveillance-tools/routine-querying-tools, Accessed 17 Jan 2020.

14. Gagne JJ, Popovic JR, Nguyen M, Sandhu SK, Greene P, Izem R, Jiang W, Wang Z, Zhao Y, Petrone AB, Wagner AK, Dutcher
SK. Evaluation of switching patterns in FDA's sentinel system: a new tool to assess generic drugs. Drug Saf. 2018;41:1313-23.

15. Dolan C. Opportunities and challenges in biosimilar uptake in oncology. Am J Manag Care. 2018;24(11 Suppl):S237-43.

16. Lockhart CM, McDermott CL, Marshall J, Mendelsohn AB, Pawloski PA, Brown J. Longitudinal evaluation of characteristics, characteristics, treatment patterns, and general outcomes among patients using granulocyte colony stimulating factors: a study by the Biologics and Biosimilars Collective Intelligence Consortium. In: National Comprehensive Cancer Network annual meeting, February 2020 (virtual). 